\title{
From the inside out and the outside in The academic library interview process in a tight economy
}

D uring times of economic distress when employment opportunities are few and the number of applicants increases, the paradigm for candidate selection and interviewing can shift in critical ways for both the candidate and the institution. Potential candidates should be even more acutely aware of the competitive environment in which they will be engaged during the search and screen process. Individuals will need to enhance their ability to market themselves. Institutions may need to re ne and rethink the parameters of any available positions, perhaps to the point of reconceptualizing the job description totally to accommodate the loss of positions and the need to consolidate professional tasks. The applicant wants to be as well prepared as possible for the interview, and the employer wants to be certain that the posted job description re ects the expectations and requirements for the advertised position.

An academic librarian must possess a range of professional quali cations and skills and have the ability to use them in numerous campus environments. As such, the search committee is responsible for personnel selection and must determine whether a candidate is a good $\mathrm{t}$ for both the library and the wider campus community. In essence, both the library and the candidate are on review during the full-search process as each tries to communicate needs, quali cations, and compatibility. An economic downturn for an institution increases the necessity to employ personnel who have an even wider range of abilities and skills and brings a heightened importance to well thought out employer needs.

The purpose of this article is to:

present practical and usable interview insights to applicant librarians unfamiliar with the academic interview; provide librarians new to serving on an academic search committee with tools and context for the interview process;

suggest ways the library can best present itself to the candidate(s);

consider the preliminary work of the search committee; and

provide information and insight for the applicant.

The academic interview may last a half day or longer. During this time a candidate may meet and interview with not only the search committee, but also with administrators and other library employees. The structure of the academic interview provides committee members the opportunity to better acquaint themselves with the candidate in a variety of settings.

\section{Perception, paperwork, and process}

A candidates rst glimpse of the library is through the job description. This snapshot of the library and institution, regardless of the breadth and depth of the position, must clearly and concisely convey its professional responsibilities and tasks. It should explicitly state application requirements, including information that might be taken for granted, for example, to whom or where application materials should be directed, including mailing address or other contact information. It is also important that the library display promptness in its contact with applicants, keeping them informed throughout the application and screening process. Key points of communication include:

Karin Durán is reference and instruction librarian, e-mail: karin.duran@csun.edu, Eric P. Garcia is reference and instruction librarian, e-mail: ericpgarcia@yahoo.com, and Mara L. Houdyshell is reference and instruction librarian, e-mail: mara.houdyshell@csun.edu, at California State University-Northridge, Oviatt Library

๑ 2009 Karin Durán, Eric P. Garcia, and Mara L. Houdyshell 
acknowledgement to the applicant when initial paperwork (resume, etc.) arrives, noti cation to the applicant of any incomplete or missing information with a request to forward needed information, and a follow-up letter or e-mail con rmation should be sent when all necessary documentation is in place.

Once qualified candidates have been identi ed, the search committee is ready to proceed to telephone interviews. During this interview, committee members should speak slowly, clearly, and converse as if the candidate is in the room. The interview with the candidate should include:

a standard greeting and outline of the interview s structure,

the names of the search committee members conducting the telephone interview, the number of questions to be asked, the interview questions, an opportunity for the candidate to ask questions, and estimated timeline for the selection of in-person interview candidates.

Once the in-person interview schedule is nalized, informational materials should be sent to the candidates, including travel and hotel information, restaurant locations, and maps of the local area and campus. If the institution is unable to fund hotel or travel costs of interviewees, make certain that candidates are made aware of this well in advance.

The day of the interview, a member of the search committee should:

greet the candidate,

point out the location of the nearest restroom,

provide a schedule of the day s events, offer a bottle of water, and

escort the candidate from location to location throughout the day.

Committee members should dress appropriately and professionally in order to accurately re ect the organization s expectations. At the beginning of the formal interview, candidates should be provided the interview questions and identifying name signs for all present should be placed around the table. Remember, perception is important; the library is under review by interviewees. Throughout the candidate $s$ visit, avoid negative body language or inattentiveness; give candidates the courtesy of full attention.

Once the best-suited candidate has been offered and accepted a position, the library should immediately notify all other applicants of the search s status. This provides closure for the individuals who were not selected, while also maintaining a cordial relationship with those who may wish to apply for a future library position.

\section{Work of the committee}

The search committee or interview panel often is responsible for a range of tasks in the recruitment and selection of a new librarian. One of the primary concerns for the committee should be creating and maintaining an unconstrained, discretionary decisionmaking process. ${ }^{1}$ Ideally this process begins early in the search through collaboration on the development of the position description. Participants in its creation should include the search committee as well as appropriate administrators and professional peers. This will result in a well thought out position description attracting candidates with a balance of various skills and experience. ${ }^{2}$

The position description must re ect all needs and avoid being too simplistic about the performance expectations. The successful academic candidate is an individual who effectively operates, not only as a professional with appropriate skills and knowledge, but also as someone who contributes to the organization on a variety of levels: department, unit, college, and university. It is also necessary for the position description to state skill, education, and experience requirements in such a way as to clearly indicate speci cs and provide easily understood values. Clear requirements not only assist prospective candidates, but add a higher level of validity to the screening and interview process.

Following the successful creation of the position description, the committee can begin to develop questions and rubrics that will 
be used to review applications. The rubric used for the initial screening of applications should be based on both the required and the desired quali cations as stated in the position description. The use of a system of weighted values for these quali cations will create a valid, easily understood, and usable method for ranking applicants quickly so that the committee can ef ciently move to the next step in the process.

The search committee is responsible for creating a practical timeline for the search process. It should also monitor the timely distribution of the position description so that the widest net can be cast, offering better opportunities for a diverse response. In addition, it is prudent to discuss and decide upon the number of in-person interviews that are anticipated from the process. This discussion and decision should be based on personnel and organizational resources. Ideally, at least three candidates should be interviewed so that the committee has a fuller understanding of the available pool and the various ways that particular candidates may meet the needs of the position.

The search committee should create rubrics for both the telephone interview and the in-person interview questions. This is a very important method of communicating the relative value and importance of required and preferred qualifications. Questions should be rmly grounded in the position description and be open-ended enough to allow candidates to demonstrate critical, analytical, and creative thinking. ${ }^{3}$

A key responsibility of the search committee is to develop an agenda for the inperson interview with a realistic timeframe, including rest periods and tour of the work environment. It is recommended that each candidate provide a public presentation as a means of performance testing, using a predetermined topic or one of the interviewee $s$ choosing. The search committee should arrange for necessary presentation equipment (computer, whiteboard, etc.) and ensure that an equipment check is made prior to the presentation. The selection of the presenta- tion location should be appropriate to the anticipated audience, including library support staff. In anticipation of each in-person interview, copies of each candidate $s$ resume should be made available for review by the librarians and staff. Following the candidate presentation, the search committee should solicit feedback from all those in attendance. The search committee should also keep the candidate(s) informed of the process and the search status.

\section{For the candidate: What to expect}

Once a candidate $s$ resume has secured an interview, the candidate may still have questions about what to expect. The following is a sample structure of the academic search and screen process as experienced from the candidate $s$ viewpoint, including preparation information and what transpires behind the scenes.

Once a potential candidate has submitted an application, he or she should receive confirmation of its receipt with general information about the selection process. Additionally, administrative forms required by the institution, such as an equal opportunity questionnaire, may be mailed to the applicant.

Candidates who meet the minimum qualifications for the position are often further screened via a telephone interview. During this interview, the committee tries to garner an overall sense of a candidate $s$ quali cations and communication skills.

Once all telephone interviews are concluded, the search committee determines which candidate(s) will be invited to the campus for an in-person interview.

The candidate should research the library, institution, and surrounding community in advance of the interview.

Comb the librarys Web pages to become familiar with the accessible information sources and the variety of services available.

If possible, make an advance trip to visit the library and ask questions at the service desks as if you were a patron. This 
provides a sense of the library s approach to public service.

If expected to give a presentation, do not rely on rote memorization. Knowing your content is more important than a wordfor-word recitation. ${ }^{4}$ Get honest feedback about your proposed presentation before the interview.

For presentations requiring media or software, check with the library well in advance as to the type of equipment that will available for use. Bring a back-up copy of your presentation if it is in a media format and at least one printed copy.

Dress professionally and comfortably.

Dining with the committee, although informal, is an important part of the interview. It is a relaxed venue that aids committee members in determining the level of $t$ between the applicant and the organization.

On the day of the interview, a candidate should come prepared with questions for the search committee that demonstrate interest and preparation for the interview. Rest assured, at some point in the day, the candidate will be asked, Do you have any questions? Additionally, some common committee interview questions include: What is your greatest strength/weakness? What interests you about this position? Where do you see yourself professionally in the next ve to ten years? If offered employment at this library, what skills do you feel that you would bring to the position?

The schedule on the actual day (or days) of an interview will be highly structured. Due to time constraints and commitments, do not become ustered if all committee members are not available for all segments of the interview. The interview schedule may include: formal, structured interview with one or more individuals or groups,

tour of the library and campus, meeting with the library dean or director, reception with support staff members, formal presentation by the candidate, question-and-answer session with librarians and/or support staff, and a meal.

\section{Conclusion}

Because the hiring process in an academic institution is multi-tiered, patience on the part of the candidate is essential. What appears to an applicant as a straightforward procedure is actually a very detailed, intricate one and often involves more than one unit on campus. There are many levels of veri cation, processing, and approval that must occur before a formal job offer can be made, and each level requires its own timeframe.

While the search committee may feel con dent that it has identi ed the best candidate, there are references to check, academic records to verify, and administrative signatures to gather. This is a process that may take a month or more. Additionally, during times of economic downturns, individual campuses or even departments within a campus may be subject to budgetary decisions that are uncertain, more time consuming, and sometimes unavoidable in a changing nancial environment.

Again, patience is vital. The two-way nature of the process demands that all participants are forthcoming and accurate in their interactions and communications in order to guarantee a mutually satisfactory outcome.

\section{Notes}

1. John A. Lehner, Reconsidering the personnel selection practices of academic libraries, Journal of Academic Librarianship 23 (May 1997): 199.

2. ACRL, A guideline for the screening and appointment of academic librarians using a search committee (2008), www.ala. org/ala/acrl/arclstandards/screenapguide. cfm (accessed October 15, 2008).

3. Susan Carol Curzon, Managing the interview: A how-to-do-it manual for hiring staff (New York: Neal-Schuman, 1995), 2135.

4. Charles S. Mudd and Malcolm O. and Sillars, Public speaking: Content and communication (Prospect Heights, IL: Waveland Press, 1991), 28182. 